\title{
EL DRAMA ARGENTINO
}

7. d drama argentino es completamente diverso al drama peruano. Hasta el momento en que escribimos-la publicación de una revista exige que los originales sean entregados con mucha anticipación-las noticias son incompletas. El ejército ha hecho declaraciones que alejan la posibilidad de una dictadura de carácter militar. En el Perú, en cambio, Sánchez Cerro no llamó a los civiles a colaborar en el gobierno, como lo hizo desde el primer momento el General Uriburu, de cepa tradicional, hombre del antiguo régimen, aunque consciente de su misión circunstancial. Uriburu se apodera del poder para acabar con el irigoyenismo, cuyos abusos habían colmado la medida. Leguía y sus paniaguados entraron a saco en los caudales públicos; destruyeron la posibilidad de una regeneración moral puesto que habían llenado el país de espías y de delatores. Irigoyen era el gaucho taimado que aspiraba a gobernar con sus solos elementos, burlándose de las otras fuerzas que se le oponían. No amordazó la prensa, porque sabía que gobernaba un país de tradición civil muy profunda; pero en cambio dió carta franca a sus partidarios para adulterar el voto popular, y él mismo «intervino» en las provincias suspendiendo en ellas todas las garantías. El drama argentino se produce por el cansancio general de la opinión, que no puede tolerar ya más esa forma de gobierno que queriendo ser democrática, se convierte en sencillamente licenciosa. Leguía gobernaba a puertas cerradas, disponía del país a su antojo, suprimía a los opositores y los encarcelaba. Su camarilla recibía favores inauditos; se enriquecía a costa de los dineros del Estado, el cual vivía en estado de servidumbre respecto de otro 
países. A Leguía no le importaba el futuro. Irigoyen no llegó nunca a la hipoteca del país.. Irigoyen era el hombre de las elecciones, el caudillo previsor en el arte de abatir adversarios políticos. Para formar su mayoría parlamentaria carecía de escrúpulos. Su mismo estado casi inconsciente, cuando en el cuartel del $7 .^{\circ}$ de Artillería se ve obligado a firmar su renuncia, es una demostración de que el movimiento revolucionario lo tomó de sorpresa, pues no creía que se produciría con el consenso del pueblo y del ejército. Sintió la opinión entera sobre su cabeza, exigiéndole el retiro inmediato. En ese momento, seguramente, recorrió de un golpe todo su gobierno y vió como nunca en el panorama argentino. Sus propios partidarios lo abandonaban: América ha dado siempre ingratitudes a cambio de servicios. Récuérdese en Chile el caso Alessandri, cuando los partidarios de la víspera ayudaron a la caída, desconociéndole todo lo que había hecho.

Irigoyen, en medio de su silencioso desprecio por la prensa, tuvo siempre gestos de rebeldía criolla para encararse con los capitalistas extranjeros. Era un nacionalista convencido que defendió las fuentes de producción nacionales. Pero no en balde había subido arrasando a las castas aristocráticas, de las que Uriburu parece ahora recoger la herencia. En el impulso del general argentino hay, sin duda, una gran parte de cansancio hacia la política radical que personificaba Irigoyen y que sentía una gran parte del país; pero tampoco puede desconocerse que, codo con codo junto a Uriburu, se mueven los elementos conservadores y aristocráticos que nunca se resignaron a la pérdida del gobierno. La oposición era cerrada y violenta y en ella participaba lo mismo el hombre de tradiciones que el hombre de apariencia democrática. El abuso en el poder trae estas contradicciones. A esto se unió la difícil situación económica: el des- 
censo en los precios de los productos que en Argentina constituían la base de la prosperidad.

Las declaraciones reiteradas de los elementos militares de que entregarán rápidamente el poder puede crear una atmósfera más limpia en el cuadro argentino. Sin embargo, se han producido ya-por lo menos así lo deja entender el cable, en los días siguientes al triunfo de Uriburu-conmociones revolucionarias que significan una reacción civil y democrática. La masa socialista en Argentina es considerable y la Federación Obrera un organismo poderoso, educado en una fuerte conciencia civil. No pueden anticiparse hechos, puesto que en los países en estado revolucionario las corrientes subterráneas se desbordan de improviso, cambiando fundamentalmente los cuadros al parecer más sólidos.

El hecho es que un destino político incierto parece guiar los pasos de esta América, que desde los días de la emancipación es un vasto panorama de persecuciones. A los emancipadores ceden los caudillos. A los caudillos, fórmulas democráticas inestables que sirven de escabel a tiranías absorbentes. Ni la aristocracia ni la llamada clase media conceden importancia al factor moralidad. La una vive de la tierra; la otra del producto. Una se apodera del gobierno, de la educación y de la política; la otra repecha la cuesta para alcanzarla. Entre ambas se mueve una masa olvidada y zaparrastrosa que sirve de elemento electoral. Durante medio siglo, las democracias americanas se debaten entre dos férreos murallones: la aristocracia y el clero. En América, aristocracia es riqueza. Es decir, latifundio. El pueblo labra la tierra, pero no la aprovecha. En cada país hay extensiones inmensas de tierra cuyos confines ni siquiera sus poseedores han cruzado alguna vez. El peculado y la venalidad representan el binomio moral de las democracias americanas. Rara vez se encuentra la dignificación del 
factor hombre, el sentido de la responsabilidad, la fuerte estructuración de una conciencia cívica. Las clases que suben al poder se corrompen, porque olvidan la justicia y porque no han sido educadas en la moral del deber y del sacrificio. Es así cómo el alba del primer aniversario de la emancipación sorprende a los países en plena orgía política. Y después de la guerra europea que desencadena todas las calamidades, sin reparar nada, sin lograr nada valioso, sino miserias y podredumbres, hace su aparición en forma ya estructurada el comunismo, cuyas lentas oleadas van, poco a poco, azotando las playas de todos los países. 